\title{
The Growth of Bismuth Sulfide Nanorods from Spherical-Shaped Amorphous Precursor Particles under Hydrothermal Condition
}

\author{
Pravas Kumar Panigrahi and Amita Pathak \\ Department of Chemistry, Indian Institute of Technology Kharagpur, Kharagpur, West Bengal 721302, India \\ Correspondence should be addressed to Amita Pathak; ami@chem.iitkgp.ernet.in
}

Received 22 October 2012; Accepted 3 January 2013

Academic Editor: Fabien Grasset

Copyright (C) 2013 P. K. Panigrahi and A. Pathak. This is an open access article distributed under the Creative Commons Attribution License, which permits unrestricted use, distribution, and reproduction in any medium, provided the original work is properly cited.

A surfactant/solid-template-free hydrothermal process has been developed for the synthesis of single-crystalline nanorods of bismuth sulfide $\left(\mathrm{Bi}_{2} \mathrm{~S}_{3}\right)$ using triethanolamine as a complexing agent for the $\mathrm{Bi}^{3+}$ ions and elemental sulfur, solubilized in monoethanolamine, as the sulfur source. X-ray diffraction and morphological studies of a series of samples synthesized at different reaction conditions suggest that the growth of nanorods occurred at the expense of the low-crystalline spherical precursor particles of aminium compounds of bismuth sulfide or bismuth sulfate formed at room temperature. In the process, the reaction condition is optimized for obtaining crystalline nanorods of pure $\mathrm{Bi}_{2} \mathrm{~S}_{3}$ with high aspect ratio. From the XRD, XPS, and HRTEM analysis of the samples, the growth of nanorods was assessed to be due to the cooperative effects of solid-solution-solid transformation and controlled oriented attachment. The hydrothermal process parameters and the presence of water in the reaction system have been found to play a crucial role in the formation of high aspect ratio nanorods. The optical band gap of the synthesized sample at optimized conditions is found to be $1.46 \mathrm{eV}$ as calculated from its diffused reflectance spectrum at room temperature.

\section{Introduction}

Bismuth sulfide $\left(\mathrm{Bi}_{2} \mathrm{~S}_{3}\right)$ is a direct band gap semiconductor with large absorption coefficient, high band gap energy (1.3$1.7 \mathrm{eV}$ ) [1], and having energy conversion efficiency close to theoretical maximum attainable value. These qualities make $\mathrm{Bi}_{2} \mathrm{~S}_{3}$ potentially suitable for the fabrication of optoelectronic and thermoelectric devices as well as applications in photovoltaic thermoelectric transport, photoconductivity, electrical photoresponse, and field emission [2-7]. Nanostructures of $\mathrm{Bi}_{2} \mathrm{~S}_{3}$, especially the one-dimensional (1D) nanostructures (such as wires, rods, tubes, and ribbons), are in fact considered to be the best contenders for these applications due to quantum confinement effect $[8,9]$. Due to quantum confinement of the charge carriers in $1 \mathrm{D}$ nanostructure, the thermoelectric efficiency of a material is enhanced through the increase in its figure-of-merit value brought about by the increase in the Seebeck coefficient and the decrease in the coefficient of thermal conductivity through boundary scattering of the heat carriers [10]. Similarly, the electron transport in crystalline nanowires is expected to be several folds faster than through a polycrystalline structure. It is because of these reasons that the optoelectronic properties of single-crystalline $1 \mathrm{D}$ nanostructures of $\mathrm{Bi}_{2} \mathrm{~S}_{3}$ have been widely studied for the design and fabrication of fast, miniaturized optoelectronic devices (such as optical switches and photodiode arrays) $[11,12]$ or for augmenting the performance of existing ones.

Due to the immense technological importance of $1 \mathrm{D}$ nanostructured $\mathrm{Bi}_{2} \mathrm{~S}_{3}$ in nanoscale devices fabrication, there has been a surge of interest in their synthesis. There has been a variety of synthetic approaches reported so far for their synthesis, which include evaporation-condensation route [1], molecular precursor decomposition route [13], solventless synthesis route [14], electrochemical deposition route [15], solvothermal/hydrothermal route [16, 17], and 
ionic liquid-assisted route [18]. Among these processes, solvothermal/hydrothermal method is one of the most studied solution-based synthesis route for the fabrication of $1 \mathrm{D}$ nanostructures of $\mathrm{Bi}_{2} \mathrm{~S}_{3}$ because this technique allows the opportunities to control the morphology of the final products through the variation of different reaction parameters, which include reaction temperature, reaction time, reaction medium (or solvent), bismuth and sulfur sources, complexing agent, and surfactant [19-21]. Besides, in the context of the possibilities to modify the growth behaviour of $\mathrm{Bi}_{2} \mathrm{~S}_{3}$ crystal to anisotropic one, the use of soft templates (such as surfactant, complexing agent, and block copolymer) as growth-directing agent has received significant amount of research interest in the recent past. Among various growthdirecting agents, the use of a complexing agent to change the growth behaviour (i.e., both nucleation and growth rate) and to confine it in a desired direction remained an interesting aspect. The complexing agents are generally polyfunctional ligands that coordinate to the surface of either the ions or the nanoparticles formed, modify the particle surface energy, and thereby enforce the unidirectional growth of the crystal. These bi- or multidentate ligands in some cases also act as a soft template in the growth process.

There are a number of reports on the synthesis of $1 \mathrm{D}$ nanostructured $\mathrm{Bi}_{2} \mathrm{~S}_{3}$ by using organic ligands, such as long chain amines, alcohols, and acids as complexing agents. Yu et al., for example, reported the use of EDTA as a coordinating agent for the preparation of $\mathrm{Bi}_{2} \mathrm{~S}_{3}$ nanorods [22]. EDTA plays multiple roles as a coordinating agent for $\mathrm{Bi}^{3+}$ as well as a soft template for the growth of nanorods under solvothermal condition [23]. On the other hand, Ota and Srivastava [24] utilized a multifunctional organic molecule (i.e., tartaric acid) as a capping agent for producing nanorods of $\mathrm{Bi}_{2} \mathrm{~S}_{3}$. Similarly, Chen et al. [25] synthesized highly crystalline $\mathrm{Bi}_{2} \mathrm{~S}_{3}$ nanorods using bismuth citrate and thiourea as precursor materials in the presence of cetyltrimethylammonium bromide. They claimed that the growth of nanorods is assisted by linear bismuth citrate polymer template. In addition, a number of polyols, for example, ethylene glycol [26], diethylene glycol (DEG) [27], and so forth, have been reported to assist in the direction-arrested one-dimensional growth of $\mathrm{Bi}_{2} \mathrm{~S}_{3}$. In this process, the multiple $-\mathrm{OH}$ groups cap the formed particles of $\mathrm{Bi}_{2} \mathrm{~S}_{3}$ and make them stable. These polyols could also exist in long chains due to the effective hydrogen bonding between them that serves as a template for growth of $\mathrm{Bi}_{2} \mathrm{~S}_{3}$ nuclei to form nanorods [27]. Triethanolamine (TEA) is another important tetradentate chelating ligand containing three $-\mathrm{OH}$ and one amine group, which, like diethylene glycol, exists as a long chain polymeric framework in the presence of water due to the effective hydrogen bonding [28]. Moreover, TEA is miscible with water in all proportions and can be used in hydrothermal process successfully. Hence, it is expected that the use of this organic ligand can be an alternative route for the synthesis of $\mathrm{Bi}_{2} \mathrm{~S}_{3}$ nanorods. However, the use of TEA for the synthesis of $1 \mathrm{D}$ nanostructure of $\mathrm{Bi}_{2} \mathrm{~S}_{3}$ powders is limited only to a few reports [29].

Therefore, the present work aims at synthesizing nanorods of $\mathrm{Bi}_{2} \mathrm{~S}_{3}$ by using TEA as a complexing agent under hydrothermal condition. In the developed process, a novel and inexpensive sulfur source, that is, elemental sulfur solubilized in monoethanolamine (MEA) has been used. The essence of this work lies in the formation of amorphous spherical precursors at room temperature and subsequently their transformation into nanorods under hydrothermal condition. A growth mechanism is also proposed.

\section{Experimental Details}

2.1. Materials. Bismuth nitrate $\left(\mathrm{Bi}\left(\mathrm{NO}_{3}\right)_{3} \cdot 5 \mathrm{H}_{2} \mathrm{O}\right)$, triethanolamine $\left.\left(\mathrm{HOC}_{2} \mathrm{H}_{4}\right)_{3} \mathrm{~N}\right)$, monoethanolamine $\left(\mathrm{HOC}_{2} \mathrm{H}_{4} \mathrm{NH}_{2}\right)$, and elemental sulfur were purchased from Merck, India, and used as received without further purification.

2.2. Synthesis. In a typical preparation, $1 \mathrm{~g}$ of bismuth nitrate was solubilized in a mixture of $20 \mathrm{~mL}$ of TEA and $120 \mathrm{~mL}$ of distilled water by stirring continuously for $1 \mathrm{~h}$. The clear solution was obtained possibly through the formation of $\left[\operatorname{Bi}(\mathrm{TEA})_{x}{ }^{3+}\right]$ complex $[29,30]$. Elemental sulfur $(0.132 \mathrm{~g})$ was separately dissolved in $10 \mathrm{~mL}$ of MEA, and it was then poured into the solution of $\left[\mathrm{Bi}(\mathrm{TEA})_{x}\right]^{3+}$ complex. A brown precipitate was obtained immediately, which turned gray within few seconds. The entire solution mixture containing the gray colored solid precursor (i.e., the precursor sol) was then transferred to a Teflon-lined stainless steel autoclave and subjected to hydrothermal reaction at $160^{\circ} \mathrm{C}$. After cooling the autoclave naturally to room temperature, the precipitates were collected, washed with water for several times and finally with ethanol, and dried. For the investigation of the reaction mechanism, the precursor sol formed at room temperature (prior to hydrothermal treatment) was also collected separately and characterized. This sample was referred to as "precursor sample" in the later part of the paper.

2.3. Characterization. The phase and structure analysis of the synthesized samples were carried out on Philips PW $1729 \mathrm{X}$-ray diffractometer using $\mathrm{Co} \mathrm{K}_{\alpha}$ radiation $(\lambda=$ $1.79 \AA$ ). X-ray photoelectron spectroscopy (XPS) studies of the samples were carried out on an XPS system made by Omicron NanoTechnology using $\mathrm{Mg} \mathrm{K}_{\alpha}(1253.6 \mathrm{eV})$ as the excitation source. The morphologies of the samples were studied by using JEOL JSM-5800 model and Zeiss EVO60 model scanning electron microscope. The chemical compositions of the samples were confirmed through energy dispersive analysis by X-ray (EDAX) using Oxford INCA electron microprobe attached to scanning electron microscope. JEOL JEM-2100 model high-resolution transmission electron microscope (HRTEM) was used to examine the microstructural details of the prepared samples. Raman spectroscopy was performed using Renishaw RM-1000 model instrument equipped with an Ar ion laser of wavelength $514.4 \mathrm{~nm}$. The diffuse reflectance spectra of the as-synthesized powders were recorded at room temperature using Varian Cary 5000 UV-Vis-NIR spectrophotometer. 


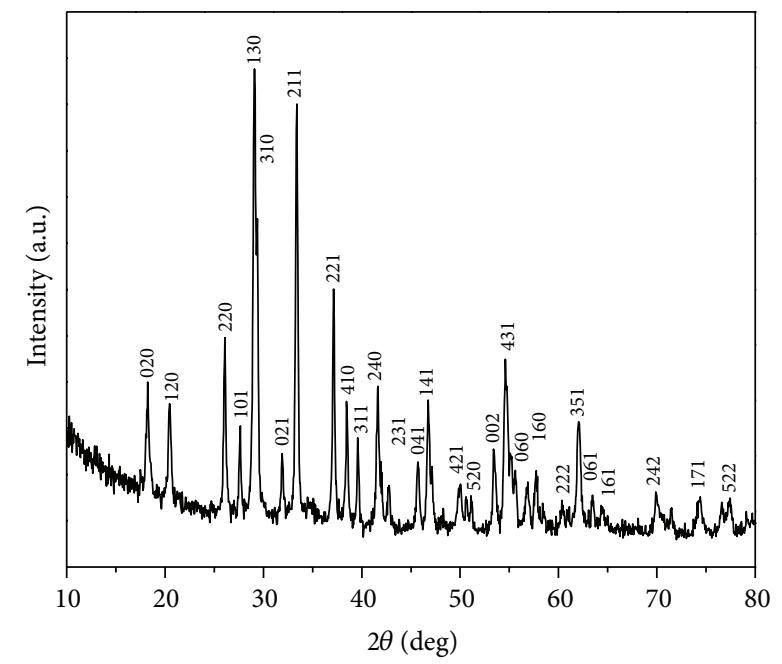

FIGURE 1: XRD pattern of the $\mathrm{Bi}_{2} \mathrm{~S}_{3}$ sample obtained after $18 \mathrm{~h}$ of hydrothermal treatment at a temperature of $160^{\circ} \mathrm{C}$.

\section{Results and Discussion}

The XRD analysis of the product, obtained after $18 \mathrm{~h}$ of hydrothermal treatment at $160^{\circ} \mathrm{C}$, is displayed in Figure 1 . The positions and relative intensities of all the peaks are in good agreement with those of the orthorhombic crystal structure of $\mathrm{Bi}_{2} \mathrm{~S}_{3}$ and are indexed according to JCPDS file number 17-0320. The calculated cell parameters ( $a=11.133 \AA$, $b=11.304 \AA$, and $c=3.977 \AA$ ) are also found to be well matched with the standard values (i.e., $a=11.14 \AA, b=$ $11.30 \AA$, and $c=3.98 \AA$ ). Within the detection limit of the XRD method, no unidentified peaks in the diffractogram are noticed, suggesting that the final product is free from impurities. Energy dispersive analysis by X-ray (EDAX) of the sample reveals S-to-Bi atomic ratio as 1.45 against the ideal value of 1.5 for pure $\mathrm{Bi}_{2} \mathrm{~S}_{3}$.

The composition of this sample was also verified by $\mathrm{X}$ ray photoelectron spectroscopy (XPS) (Figure 2). The survey spectrum (Figure 2(a)) reveals the presence of elements, such as $\mathrm{Bi}, \mathrm{S}, \mathrm{O}$, and $\mathrm{C}$, which indicates the high purity of the resulting product. The peak for $\mathrm{O}$ arises, possibly, due to the adsorbed gases and/or oxides of $\mathrm{C}$ on the surfaces of the samples [29]. This observation is common in case of ultrafine powder samples when exposed to atmosphere. The high resolution XPS spectra in Bi region (Figure 2(b)) shows two peaks at 157.7 and $163 \mathrm{eV}$, which can be assignable, respectively, to the binding energies of $B i 4 f_{7 / 2}$ and $B i 4 f_{5 / 2}$ in $\mathrm{Bi}_{2} \mathrm{~S}_{3}$. The broad peak at around $224.9 \mathrm{eV}$ (Figure 2(c)) corresponds to the binding energy of $S 2$ s. The observed values are found to be in close agreement with the data reported by Grigas et al. [31]. Raman spectroscopy studies were carried out to further validate the composition of the samples. Room-temperature Raman spectrum (recorded between 200 and $1400 \mathrm{~cm}^{-1}$ ) for the sample obtained after $18 \mathrm{~h}$ of hydrothermal treatment at $160^{\circ} \mathrm{C}$ is displayed in Figure 3 . The spectrum depicts five distinct vibrational peaks at about $260,306,422,606$, and $965 \mathrm{~cm}^{-1}$, which corresponds to the characteristic Raman bands of crystalline $\mathrm{Bi}_{2} \mathrm{~S}_{3}$ samples [24]. These are also in good agreement with the nanoparticles of $\mathrm{Bi}_{2} \mathrm{~S}_{3}$ reported by Rabin et al. $[7,32]$.

The particle morphologies of the synthesized $\mathrm{Bi}_{2} \mathrm{~S}_{3}$ powders were studied by electron microscopy. Representative SEM and bright field TEM micrographs of the sample obtained after $18 \mathrm{~h}$ of hydrothermal treatment at $160^{\circ} \mathrm{C}$ are shown in Figures 4(a) and 4(b), respectively. The micrographs reveal the formation of nanorods of $\mathrm{Bi}_{2} \mathrm{~S}_{3}$ with average diameters and lengths ranging between 70 and $170 \mathrm{~nm}$ and $0.550-$ $3 \mu \mathrm{m}$, respectively. TEM image of a typical nanorod having diameter of $90 \mathrm{~nm}$ and length of $2.5 \mu \mathrm{m}$ and its detailed lattice fringe pattern are illustrated in Figures 4(c) and 4(d), respectively. The calculated fringe width of $0.56 \mathrm{~nm}$ (shown in Figure 4(d)) matches with the d-spacing of the (200) planes of the orthorhombic $\mathrm{Bi}_{2} \mathrm{~S}_{3}$ crystal [12], suggesting that the growth of the nanorods of $\mathrm{Bi}_{2} \mathrm{~S}_{3}$ occurred along the preferential [001] ( $c$-axis) direction. Furthermore, the spotted pattern of the selected area electron diffraction (SAED) of the selected nanorod (shown as an inset in Figure 4(d)) infers single-crystalline nature of the synthesized sample.

In order to investigate the possible growth mechanism and the chemistry involved in the synthesis of $\mathrm{Bi}_{2} \mathrm{~S}_{3}$ nanorods, a series of samples were synthesized at different reaction conditions and were analyzed by XRD and electron microscopy. Figure 5 represents the XRD patterns of the room-temperature precipitate that was separated prior to hydrothermal treatment and the samples obtained after 1, 3, and $12 \mathrm{~h}$ of hydrothermal treatment at a fixed temperature of $160^{\circ} \mathrm{C}$. XRD pattern in Figure 5(a) showed broad and diffused peaks centered at around $2 \theta=30.88^{\circ}, 35.23^{\circ}$, and $51.73^{\circ}$ indicating the precursor sample to be predominantly amorphous. The positions of these diffused peaks are slightly shifted from the standard values of major peaks reported for the orthorhombic $\mathrm{Bi}_{2} \mathrm{~S}_{3}$ phase (JCPDS file no. 17-0320) but could not be assigned to any compound reported in the available literature. These unidentified broad peaks were however observed to diminish in intensity and eventually disappeared to give way to diffraction lines characteristic of the pure $\mathrm{Bi}_{2} \mathrm{~S}_{3}$ phase. This could be achieved through hydrothermal treatment of the precursors at temperatures $\geq 160^{\circ} \mathrm{C}$ and incubation periods $\geq 6 \mathrm{~h}$ (see Figure S1 in Supplementary Material available online at http://dx.doi.org/10.1155/2013/367812). It was interesting to note that though the orthorhombic phase of $\mathrm{Bi}_{2} \mathrm{~S}_{3}$ was realized through hydrothermal processing of the precursors at temperatures as low as $120^{\circ} \mathrm{C}$ and incubation period of just $3 \mathrm{~h}$, but it was accompanied by the highest intense peak (at $2 \theta \approx 30.28^{\circ}$ ) of the unidentified phase. It was also realized that this peak persisted even though it prolonged the incubation period to $24 \mathrm{~h}$ at a temperature of $120^{\circ} \mathrm{C}$. The peak however diminished in intensity with an increase in hydrothermal temperatures beyond $120^{\circ} \mathrm{C}$, and in effect, the pure orthorhombic phase of $\mathrm{Bi}_{2} \mathrm{~S}_{3}$ was accomplished on hydrothermal processing of the precursors at $160^{\circ} \mathrm{C}$ for $12 \mathrm{~h}$ (Figure 5(d)), although the products after 1 and $3 \mathrm{~h}$ of heating periods contain some amount of unidentified phase (as indicated by ${ }^{*}$ in Figures 5(b) and 5(c)). On the basis of optimization studies, however, the pure and crystalline phases of $\mathrm{Bi}_{2} \mathrm{~S}_{3}$ with relatively high aspect ratio were obtained 


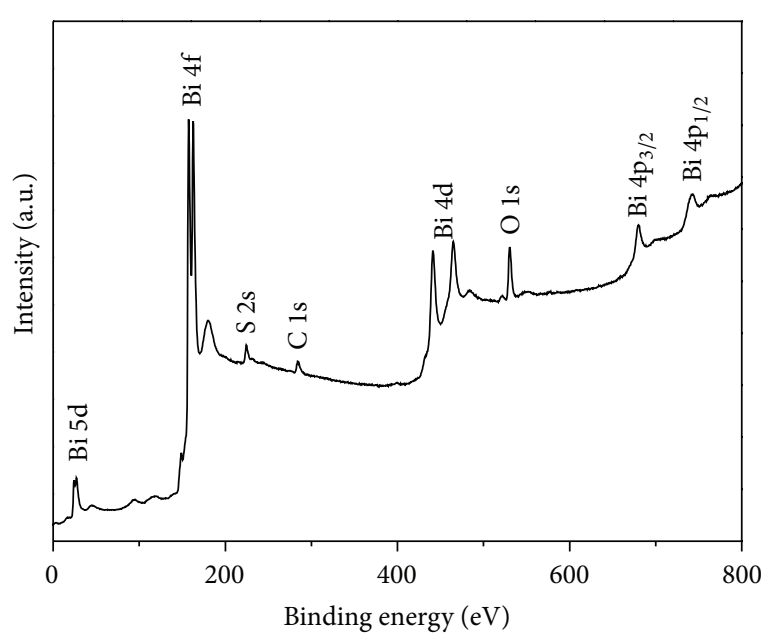

(a)

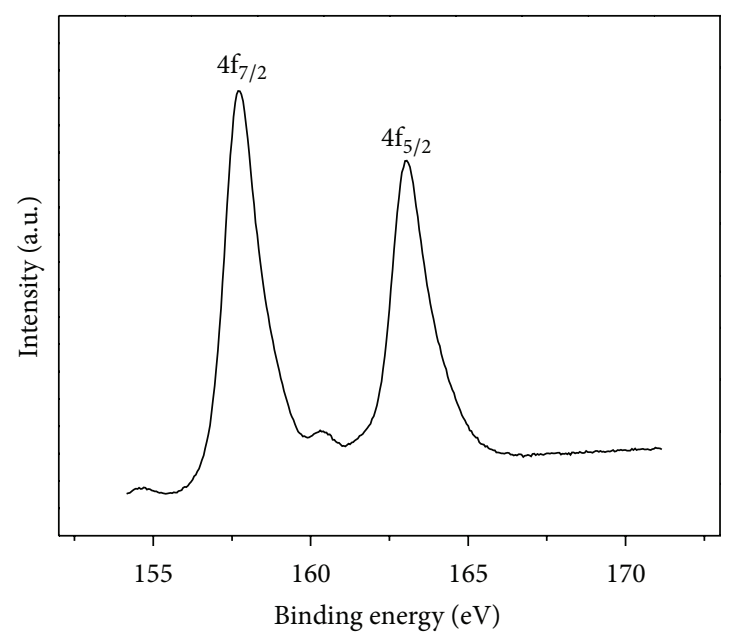

(b)

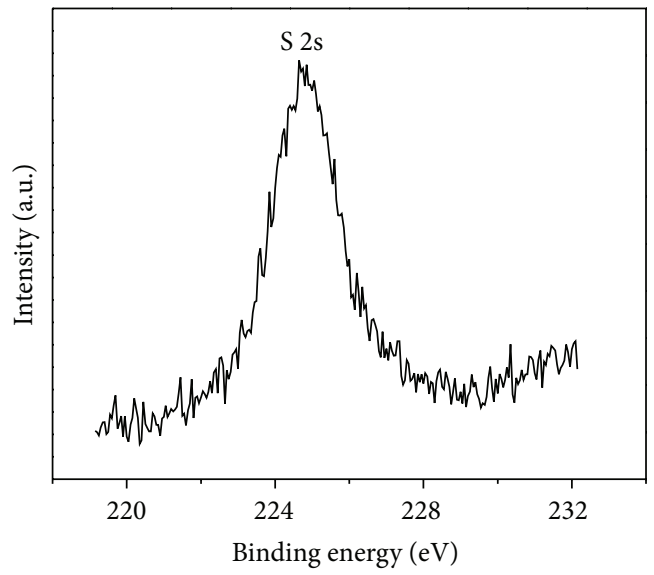

(c)

FIGURE 2: XPS analysis of $\mathrm{Bi}_{2} \mathrm{~S}_{3}$ synthesized after $18 \mathrm{~h}$ of hydrothermal treatment at a temperature of $160^{\circ} \mathrm{C}$; (a) survey spectra, (b) Bi region, and (c) $\mathrm{S}$ region.

on hydrothermal processing of the precursors at $160^{\circ} \mathrm{C}$ for $18 \mathrm{~h}$, as depicted in Figure 1.

It may thus be inferred that the broad peaks of the precursors (at $2 \theta=30.88^{\circ}, 35.23^{\circ}$, and $51.73^{\circ}$ ) correspond to an intermediate compound that are poorly crystalline and decompose to $\mathrm{Bi}_{2} \mathrm{~S}_{3}$ at hydrothermal processing temperatures $\geq 160^{\circ} \mathrm{C}$ and incubation period $\geq 6 \mathrm{~h}$. Liu et al. [16] reported the formation of similar intermediates, which decomposed to generate $\mathrm{Bi}_{2} \mathrm{~S}_{3}$ nanoribbons. They assigned the broad peaks located at $2 \theta \approx 30.57^{\circ}, 29.62^{\circ}$, and $52.75^{\circ}$ to cubic $\mathrm{NaBiS}_{2}$, which got formed through hydrothermal reaction between $\mathrm{Bi}^{3+}$-glycerol complexes and elemental sulfur $/ \mathrm{Na}_{2} \mathrm{~S}_{2} \mathrm{O}_{3}$ in aqueous solution of $\mathrm{NaOH}$. Ota and Srivastava [33] also predicted the formation of $\mathrm{Bi}_{2} \mathrm{~S}_{3}$ nanotubes via decomposition of $\mathrm{NH}_{4} \mathrm{BiS}_{2}$ intermediates that were claimed to be produced from the reaction of $\left[\mathrm{Bi}(\mathrm{TEA})_{x}\right]^{3+}$ complex with $\mathrm{CS}_{2}$ and $\mathrm{NH}_{3}$ in presence of Triton X-100 under hydrothermal condition. It was noted that the observed $2 \theta$ values of our precursors were slightly shifted from those reported for the cubic $\mathrm{NaBiS}_{2}$ phase. Therefore, based on these observations and drawing analogies with the reported literature in conjunction with the knowledge of the reagents involved in the present preparation, we can rationally predict the intermediates (precursors) to be aminium compounds of bismuth sulfide $\left[\left(\mathrm{BiS}_{2}\right)^{-}\right]$or thiosulfate $\left[\left[\mathrm{Bi}\left(\mathrm{S}_{2} \mathrm{O}_{3}\right)\right]^{3-}\right]$. Hydrothermal processing of these precursors probably generates nanorods of $\mathrm{Bi}_{2} \mathrm{~S}_{3}$. It however needs to be mentioned that though $\mathrm{Na}_{3} \mathrm{Bi}\left(\mathrm{S}_{2} \mathrm{O}_{3}\right)_{3} \cdot n \mathrm{H}_{2} \mathrm{O}$ and $\mathrm{NaBiS}_{2}$ are reported in the literature $[16,34]$, the existence of aminium/ammonium intermediates is difficult to establish through XRD studies because of their poor crystalline nature and nonavailability of the standard literature claiming their formation in the crystalline form.

In order to substantiate the prediction from XRD analysis, the composition of the precursor sample (collected prior to hydrothermal treatment) was further studied by XPS. The survey spectrum, shown in Figure 6(a), reveals the presence of $\mathrm{Bi}, \mathrm{S}, \mathrm{O}, \mathrm{N}$, and $\mathrm{C}$. Here, $\mathrm{C}$ 1s with standard binding energy (BE) value of $284.6 \mathrm{eV}$ is taken as a reference. As $\mathrm{C} 1 \mathrm{~s}$ peak in Figure 6(a) lies at $285.5 \mathrm{eV}$, instead of its ideal 


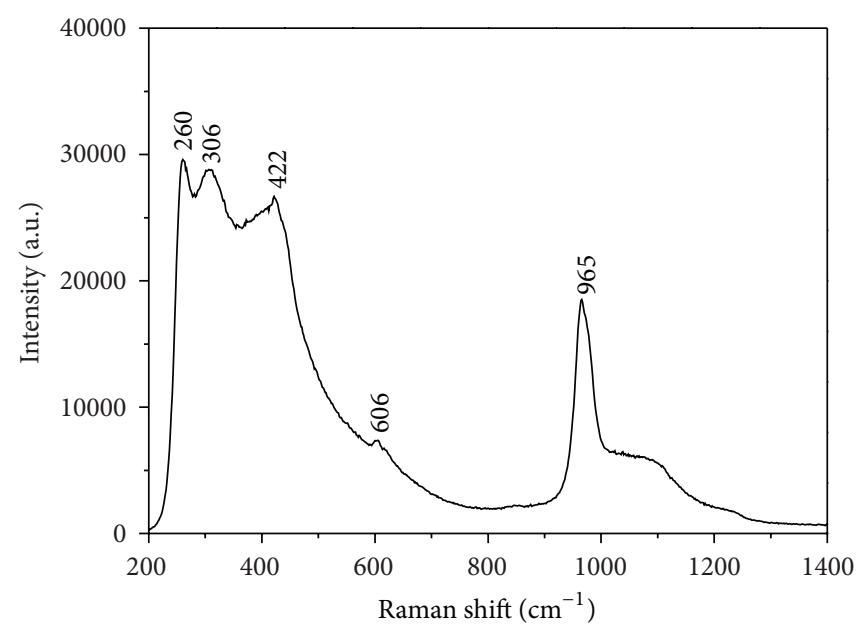

FIgURE 3: Raman spectra of the $\mathrm{Bi}_{2} \mathrm{~S}_{3}$ sample synthesized through hydrothermal process at $160^{\circ} \mathrm{C}$ and incubation time period of $18 \mathrm{~h}$.

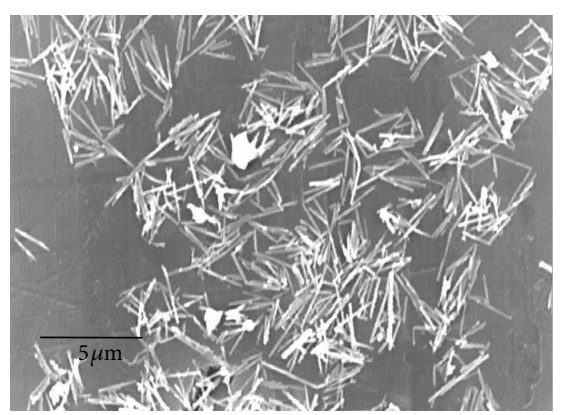

(a)

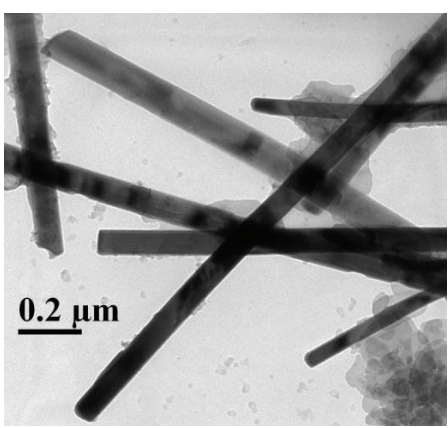

(b)

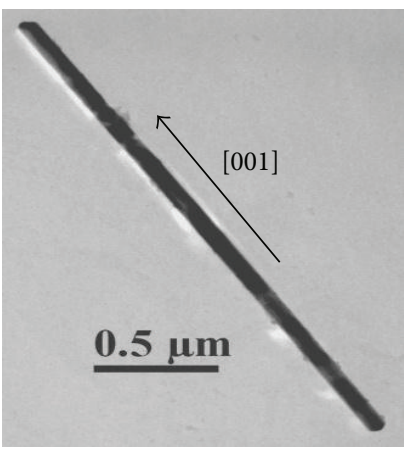

(c)

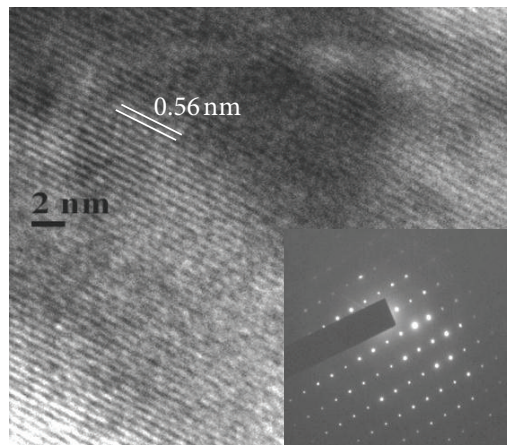

(d)

FIGURE 4: $\mathrm{Bi}_{2} \mathrm{~S}_{3}$ sample obtained through hydrothermal process at $160^{\circ} \mathrm{C}$ after $18 \mathrm{~h}$ of incubation period; (a) SEM image, (b) corresponding TEM image, (c) TEM image of a selected nanorod, and (d) HRTEM image of the selected nanorod with the corresponding SAED pattern (inset).

value of $284.6 \mathrm{eV}$, all the observed BEs in the XPS analysis are corrected accordingly $[35,36]$. The small peak around $400 \mathrm{eV}$ in survey spectrum may be attributed to $\mathrm{N}$ 1s of amine analogue $[37,38]$ present in the precursor sample, that is, aminium compounds of $\left(\mathrm{BiS}_{2}\right)^{-}$and $\left[\mathrm{Bi}\left(\mathrm{S}_{2} \mathrm{O}_{3}\right)_{3}\right]^{3-}$. The standard $2 \mathrm{~s}$ binding energy for sulfur in their elemental state is reported to be $229 \mathrm{eV}$ [39], which is lowered by $3 \mathrm{eV}$ for $\mathrm{S}^{2-}$ state in $\mathrm{Bi}_{2} \mathrm{~S}_{3}$ [31]. So, the peak at $228 \mathrm{eV}$ in Figure 6(b) may be assigned to $2 \mathrm{~s} \mathrm{BE}$ for $\mathrm{S}^{2-}$ state in $\left(\mathrm{BiS}_{2}\right)^{-}$species. On the other hand, the peak at $231.5 \mathrm{eV}$, which is higher than $2 \mathrm{~s}$ $\mathrm{BE}$ for $\mathrm{S}^{0}$ but lower than $S^{6+}$ state in sulfate ion [38], may be assigned to the presence of $\mathrm{S}_{2} \mathrm{O}_{3}{ }^{2-}$ species $\left(\mathrm{S}^{2+}\right.$ state) in the precursor sample. In addition, the strong peak for $\mathrm{O} 1 \mathrm{~s}$ in the survey spectrum (Figure 6(a)) could be deconvoluted into two peaks ( 531.1 and $533.6 \mathrm{eV}$ ). These two deconvoluted peaks could respectively be assigned to $\mathrm{S}_{2} \mathrm{O}_{3}{ }^{2-}$ species and 


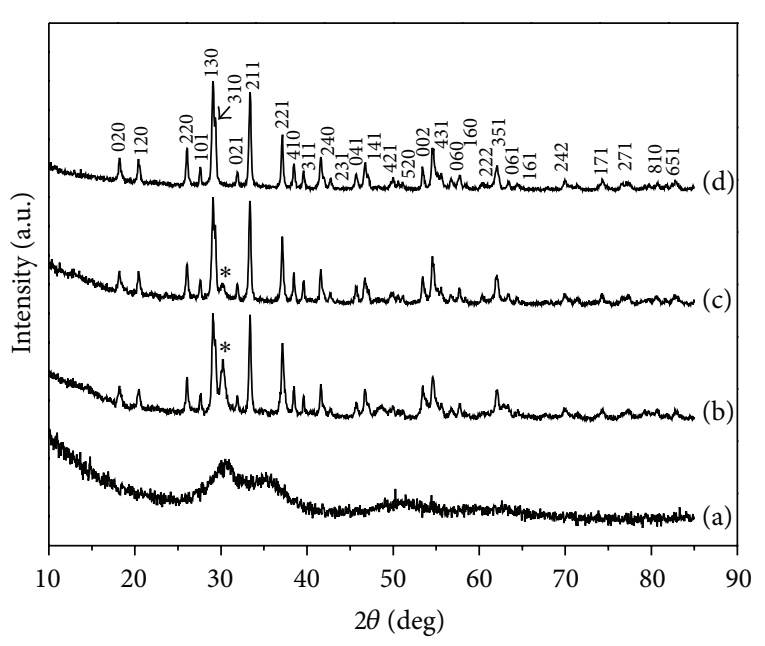

FIGURE 5: XRD patterns of the samples synthesized at different conditions; (a) at room temperature, after hydrothermal treatment at $160^{\circ} \mathrm{C}$ for (b) $1 \mathrm{~h},(\mathrm{c}) 3 \mathrm{~h}$, and (d) $12 \mathrm{~h}$.

to adsorbed $\mathrm{CO}_{2}$ in the sample [38]. The peak pair at 159.5 and $164.5 \mathrm{eV}$ (in Figure 6(c)) is close to binding energies of $\mathrm{Bi}$ $4 \mathrm{f}_{7 / 2}$ and $\mathrm{Bi} 4 \mathrm{f}_{5 / 2}$ in $\mathrm{Bi}_{2} \mathrm{~S}_{3}$ [13] and can be assigned to $\mathrm{Bi}^{3+}$ in $\left(\mathrm{BiS}_{2}\right)^{-}$or $\left[\mathrm{Bi}\left(\mathrm{S}_{2} \mathrm{O}_{3}\right)_{3}\right]^{3-}$ species. This is because $\mathrm{Bi}^{3+}$ is not very sensitive to chemical environment; therefore, $\left(\mathrm{BiS}_{2}\right)^{-}$ or $\left[\mathrm{Bi}\left(\mathrm{S}_{2} \mathrm{O}_{3}\right)_{3}\right]^{3-}$ species are expected to show ionization potential values comparable to $\mathrm{Bi}_{2} \mathrm{~S}_{3}$.

Based on the above experimental results, the possible chemistry involved in the preparation of $\mathrm{Bi}_{2} \mathrm{~S}_{3}$ can be proposed. As it is already discussed in our previous paper [40] that the disproportionation reaction of solution of elemental sulfur in MEA generates a number of ions including thiosulfate $\left(\mathrm{S}_{2} \mathrm{O}_{3}{ }^{2-}\right)$ and $\mathrm{HS}^{-}$ions in the presence of $\mathrm{OH}^{-}$ ions in the reaction mixture. The TEA chelated complexes of bismuth ions react then with the $\mathrm{S}^{2-}$ and $\mathrm{S}_{2} \mathrm{O}_{3}{ }^{2-}$ ions at room temperature to produce aminium compounds of bismuth sulfide and thiosulfate (i.e., $\left(\mathrm{BiS}_{2}\right)^{-}$and $\left[\mathrm{Bi}\left(\mathrm{S}_{2} \mathrm{O}_{3}\right)\right]^{3-}$ ) as per reactions (1) and (2):

$$
\begin{aligned}
\mathrm{Bi}^{3+}+2 \mathrm{~S}^{2-} & \rightleftharpoons\left[\mathrm{BiS}_{2}\right]^{-} \\
\mathrm{Bi}^{3+}+3 \mathrm{~S}_{2} \mathrm{O}_{3}{ }^{2-} & \rightleftharpoons\left[\mathrm{Bi}\left(\mathrm{S}_{2} \mathrm{O}_{3}\right)_{3}\right]^{3-}
\end{aligned}
$$

Under hydrothermal processing, the aminium compounds of $\left[\mathrm{Bi}\left(\mathrm{S}_{2} \mathrm{O}_{3}\right)\right]^{3-}$ are first converted into the corresponding $\left(\mathrm{BiS}_{2}\right)^{-}$, which subsequently undergoes decomposition to generate $\mathrm{Bi}_{2} \mathrm{~S}_{3}$ nanocrystals. These nanocrystals probably grow into $1 \mathrm{D}$ nanostructures of $\mathrm{Bi}_{2} \mathrm{~S}_{3}$ with increasing the incubation period. The whole process thus can be summarized through the following set of chemical reactions:

$$
\begin{gathered}
{\left[\mathrm{Bi}\left(\mathrm{S}_{2} \mathrm{O}_{3}\right)_{3}\right]^{3-} \stackrel{\text { Hydrothermal processing }}{=}\left[\mathrm{BiS}_{2}\right]^{-}} \\
2\left[\mathrm{BiS}_{2}\right]^{-} \stackrel{\text { Hydrothermal processing }}{\rightleftharpoons} \mathrm{Bi}_{2} \mathrm{~S}_{3} \text { (nanocrystals) }+\mathrm{S}^{2-} \\
n\left(\mathrm{Bi}_{2} \mathrm{~S}_{3}\right) \stackrel{\text { hydrothermal }}{\longrightarrow}\left(\mathrm{Bi}_{2} \mathrm{~S}_{3}\right)_{n}
\end{gathered}
$$

To further study the possible growth mechanism of the formation of one-dimensional structures of $\mathrm{Bi}_{2} \mathrm{~S}_{3}$, the effect of reaction temperature and reaction time on the morphologies of the samples were studied exhaustively by electron microscopy. Figure 7(a) depicts TEM image of the precursor sample obtained prior to hydrothermal treatment, which suggests the presence of mostly aggregation of nearly spherical nanoparticles of diameters in the range of $20-40 \mathrm{~nm}$. These aggregates are amorphous in nature as indicated from its diffused SAED patterns (inset of Figure 7(a)). This finding is also supported by XRD analysis (Figure 5(a)). Figure 7(b) reveals that the nanorod-shaped morphologies get formed even after $1 \mathrm{~h}$ of hydrothermal processing at $160^{\circ} \mathrm{C}$, though some agglomerated spherical particles are still present. With the increase of the incubation to $12 \mathrm{~h}$, the number of rod-shaped particles of $\mathrm{Bi}_{2} \mathrm{~S}_{3}$ increased, while the spherical aggregates reduced drastically (Figure $7(\mathrm{c})$ ). Pure crystalline nanorods of $\mathrm{Bi}_{2} \mathrm{~S}_{3}$ were eventually realized on increasing the incubation period to $18 \mathrm{~h}$ at the hydrothermal reaction temperature of $160^{\circ} \mathrm{C}$ (as shown in Figure 4(a)). It is interesting to note that on increasing the heating period to $24 \mathrm{~h}$, a few nanowires of $\mathrm{Bi}_{2} \mathrm{~S}_{3}$ (indicated by arrows in Figure 7(d)) are also formed amidst a pool of nanorods.

The effect of reaction temperature on the morphology of the synthesized $\mathrm{Bi}_{2} \mathrm{~S}_{3}$ sample was also investigated by varying the reaction temperature in the range of $120-180^{\circ} \mathrm{C}$ for a fixed incubation period (i.e., $6 \mathrm{~h}$ ). The SEM images of the synthesized samples at hydrothermal temperatures 120, 140, 160 , and $180^{\circ} \mathrm{C}$ (Figure S2, Supporting Information) suggest that rod-like morphologies with diameters in nanometer range are formed after $6 \mathrm{~h}$ of incubation period irrespective of the hydrothermal reaction temperature. However, some aggregated masses were visible, when the reaction was carried out at a lower temperature, which gradually disappeared as the temperature was increased. It can thus be inferred that the growth of nanorods occurs probably at the expense of amorphous spherical particles.

Based on the morphological findings and other experimental observations, it is thus possible to propose a growth mechanism for the preparation of $\mathrm{Bi}_{2} \mathrm{~S}_{3}$. As it was already mentioned earlier, a large numbers of $\mathrm{Bi}_{2} \mathrm{~S}_{3}$ nuclei are generated as a result of the decomposition of the precursors at the initial stage of the hydrothermal reaction. These freshly formed nanocrystals or nuclei in the solution are unstable due to the presence of a large number of dangling bonds, defects, or traps on the nuclei surfaces. Hence, under hydrothermal 


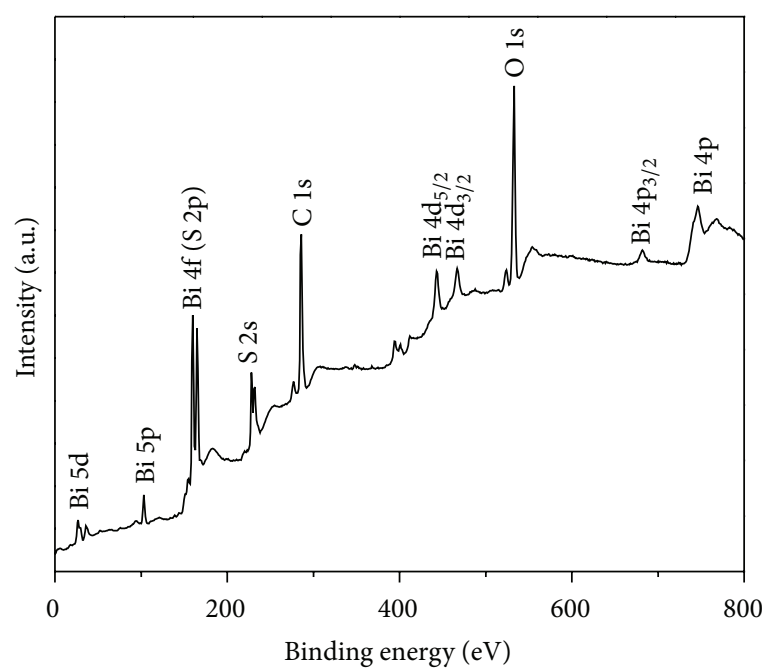

(a)

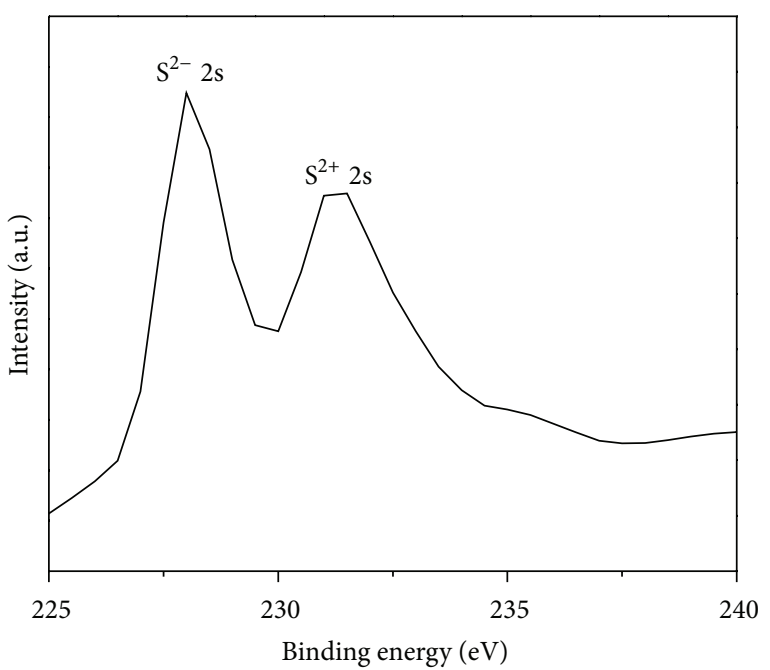

(b)

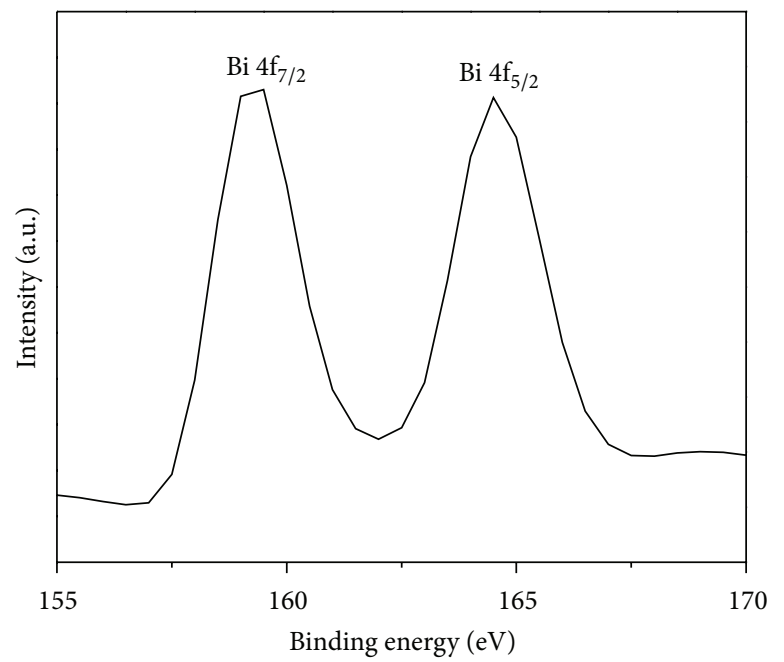

(c)

FIGURE 6: XPS analysis of the precursor sample; (a) survey spectra, (b) S region, and (c) Bi region.

condition, the smaller $\mathrm{Bi}_{2} \mathrm{~S}_{3}$ nanocrystals precipitate onto comparatively larger particles, leading to growth of the crystals along the energetically favorable direction (i.e., $c$ direction) to form the nanorods of $\mathrm{Bi}_{2} \mathrm{~S}_{3}$. The proposed growth mechanism agrees with the morphological findings, where it is evident that with the increase in the incubation period, the $\mathrm{Bi}_{2} \mathrm{~S}_{3}$ particles grew more rapidly along the length compared to the diameters. This oriented crystal growth can be attributed to the typical anisotropic layered structure of $\mathrm{Bi}_{2} \mathrm{~S}_{3}$. The process is also thermodynamically driven by the decrease in the total interfacial energy of the particles as a result of merging. An analogous mechanism was suggested by Zhu et al. [41] for the growth of nanorods from the initially formed $\mathrm{Bi}_{2} \mathrm{~S}_{3}$ particles through a dynamic equilibrium: $2 \mathrm{Bi}^{3+}+3 \mathrm{~S}^{2-} \leftrightarrow \mathrm{Bi}_{2} \mathrm{~S}_{3}$. They proposed that the $\mathrm{Bi}^{3+}$ and $\mathrm{S}^{2-}$ ions, which were in equilibrium in solution, precipitated onto larger particles, thereby decreasing the total interfacial energy between the particles and the solution.
Liu et al. [16] recognized a similar growth sequence for the fabrication of $\mathrm{Bi}_{2} \mathrm{~S}_{3}$ nanoribbons from $\mathrm{NaBiS}_{2}$ precursors through solvothermal process, but they choose to call the mechanism as "solid-solution-solid (SSS) transformation". Gates et al. [42] also proposed the synthesis of single-crystal nanowires of selenium from spherical colloidal particles of amorphous selenium in aqueous solution through similar mechanism and called it to be SSS transformation. Based on the discussion, the formation and the overall growth process of the $\mathrm{Bi}_{2} \mathrm{~S}_{3}$ nanorods through hydrothermal process can be schematically represented by a sketch as shown in Figure 8.

On the other hand, the formation of longer rods or wires of $\mathrm{Bi}_{2} \mathrm{~S}_{3}$ (as shown in Figure $7(\mathrm{~d})$ ) probably occurred at the expense of small rod-shaped particles, which merged to reduce the net interfacial energy of the particles. This prediction is supported by bright field TEM images obtained for the sample synthesized at a hydrothermal temperature of $160^{\circ} \mathrm{C}$ for a period of $18 \mathrm{~h}$ (Figure 9). The contrast variation 


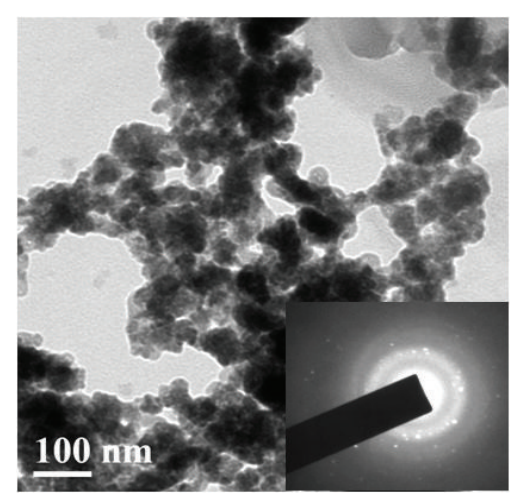

(a)

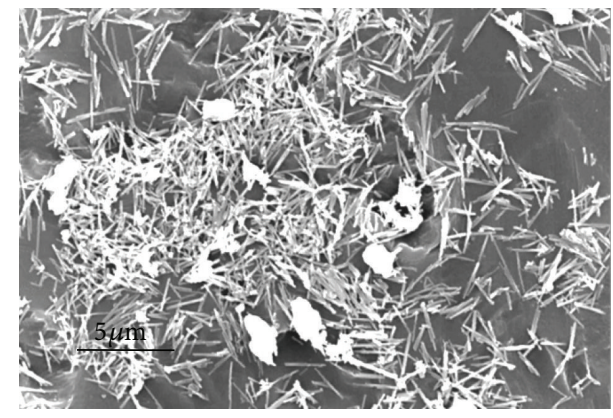

(c)

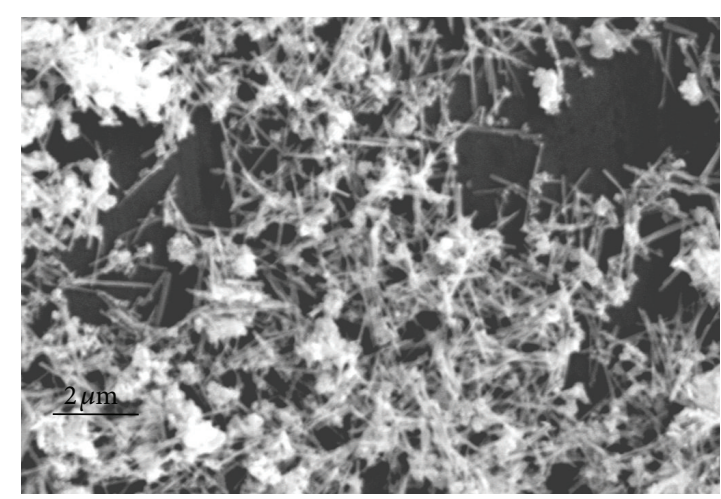

(b)

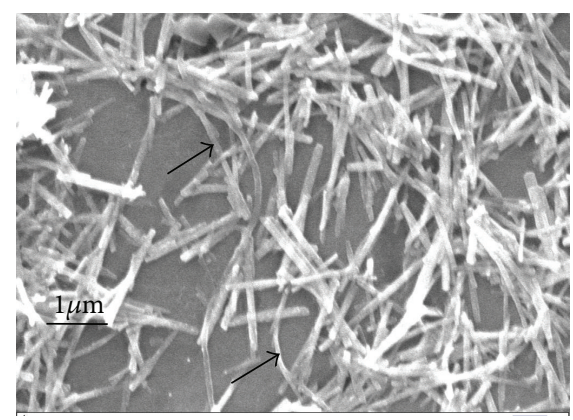

(d)

FIGURE 7: (a) TEM image of precursor sample and the corresponding SAED pattern (inset) and SEM images of the sample obtained through hydrothermal treatment at $160^{\circ} \mathrm{C}$, (b) after $1 \mathrm{~h},(\mathrm{c})$ after $12 \mathrm{~h}$, and (d) after $24 \mathrm{~h}$.

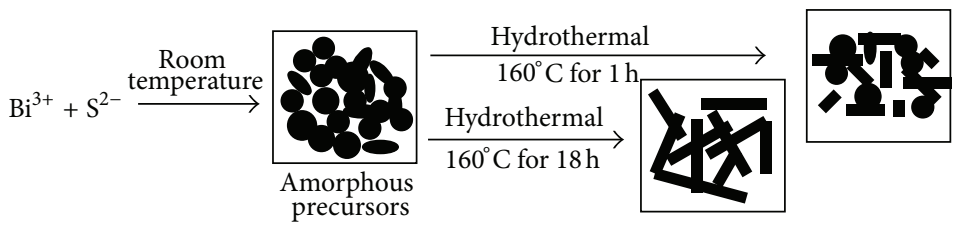

FIGURE 8: Schematic representation of the growth of $\mathrm{Bi}_{2} \mathrm{~S}_{3}$ nanorods from spherical nanoparticles of precursors through hydrothermal process.

of TEM images (shown in Figures 9(a) and 9(b)) clearly depicts the joining of a pair of $\mathrm{Bi}_{2} \mathrm{~S}_{3}$ nanorods. It can be seen from the images that rods are continuous across the connected part barring at some portions. For further insight into the microstructure at the junction, the encircled portion of the TEM image was magnified (Figure 9(c)), which shows the lattice planes at the joint. Lattice spacing, calculated from the fringe pattern of the HRTEM image, is found to be $0.476 \mathrm{~nm}$ corresponding to (120) plane of orthorhombic phase of $\mathrm{Bi}_{2} \mathrm{~S}_{3}$. It can be seen from images that fringes are almost continuous across the joint with disrupted continuity only at selected area. The disrupted portion is indicated by an arrow in Figure 9(c).

It can thus be predicted that under hydrothermal conditions, fusion of the particles at the interface takes place only when joining particles are suitably positioned so as to share a common crystallographic orientation. A similar morphological sequence has also been observed by Yu et al. [43] for the synthesis of nanowires of $\mathrm{Bi}_{2} \mathrm{~S}_{3}$ from spherical crystals. They suggested that the formation of nanowires of $\mathrm{Bi}_{2} \mathrm{~S}_{3}$ occurred via merging of short nanorods under hydrothermal reaction at $180^{\circ} \mathrm{C}$ (for 3 days) of the solution containing spherical crystals of $\mathrm{Bi}_{2} \mathrm{~S}_{3}$. Deng et al. [23] explained the fabrication of sheet rods of $\mathrm{Bi}_{2} \mathrm{Te}_{3}$ on the basis of EDTA-assisted controlling oriented attachment of individual sheets. They too proposed that the joining process was thermodynamically driven by the reduction in the net surface energy of the particles, and the joining of particles was possible, only when they had common crystallographic orientation. On the basis of the present discussion, it can thus be inferred that both controlled oriented attachment and SSS mechanism cooperate in the formation of nanorods/wires of $\mathrm{Bi}_{2} \mathrm{~S}_{3}$ from smaller rods/spherical particles in the hydrothermal process.

In the developed process, TEA, which serves as a stabilizing agent for retaining the bismuth ions in solution through complex formation as well as an efficient capping 


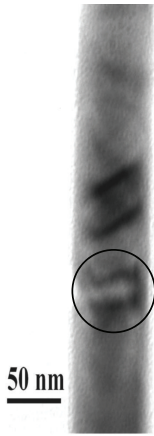

(a)

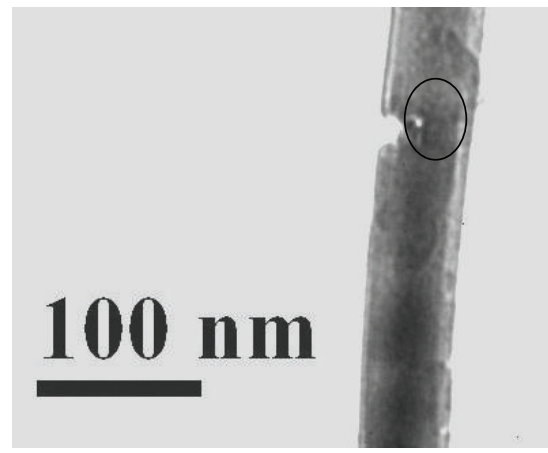

(b)

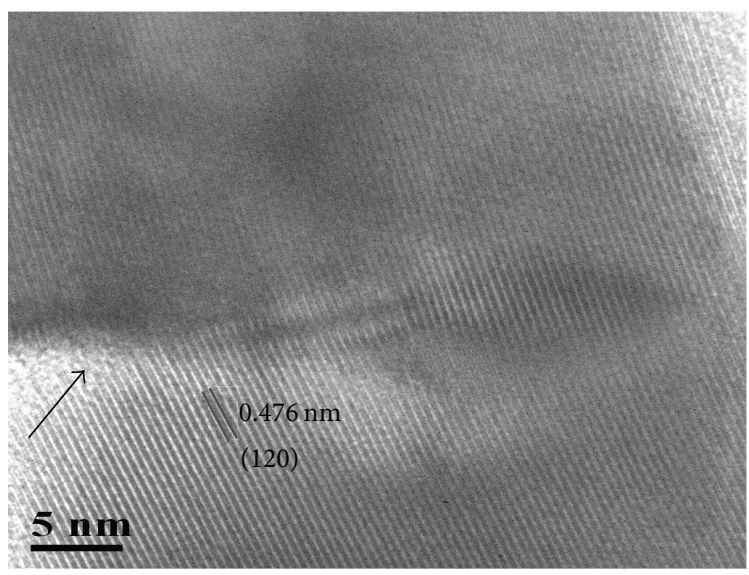

(c)

FIGURE 9: TEM images showing the joining of a pair of $\mathrm{Bi}_{2} \mathrm{~S}_{3}$ rods (marked by circles); (a) at low resolution, (b) high resolution of image of the encircled portion in (b), and (c) high resolution of image showing the fringe patterns at the joint.

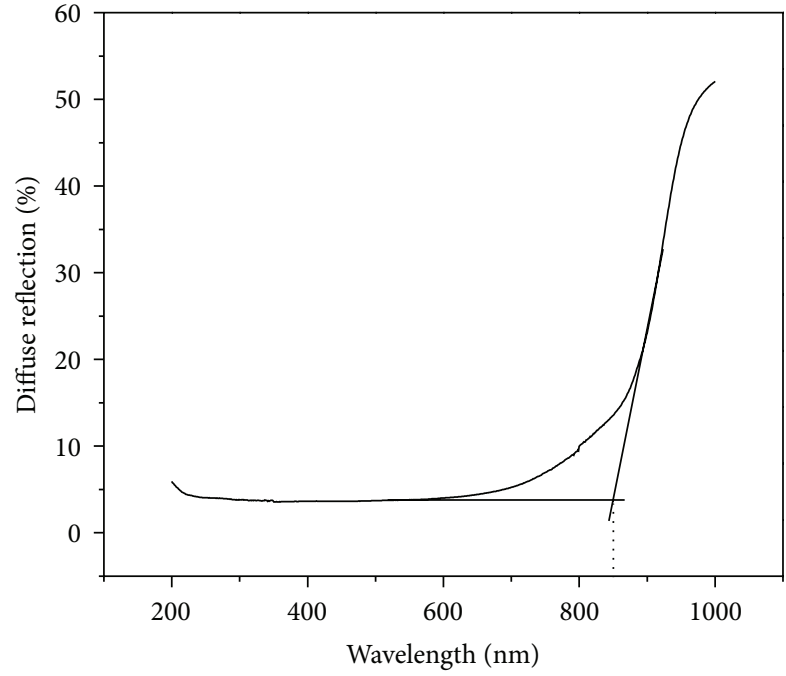

Figure 10: Diffuse reflectance spectra of the $\mathrm{Bi}_{2} \mathrm{~S}_{3}$ samples, synthesized through hydrothermal process at a temperature of $160^{\circ} \mathrm{C}$ and incubation period of $18 \mathrm{~h}$.

agent $[44,45]$, also plays another important role in the formation of shape-controlled $1 \mathrm{D}$ structures of $\mathrm{Bi}_{2} \mathrm{~S}_{3}$. TEA is a tetradentate ligand with three $-\mathrm{OH}$ groups and one amine group that effectively coordinates to the ions or particles, and thereby modifies the surface energy states of the particles, making them to grow in one dimension. In the aqueous reaction mixture, the unchelated, free TEA probably forms long chain polymeric framework [28] due to hydrogen bonding. These structures may help in assembling the initially formed nearly spherical particles to grow in one dimension under hydrothermal condition leading to the generation of uniformly sized pure and crystalline $1 \mathrm{D}$ structures of $\mathrm{Bi}_{2} \mathrm{~S}_{3}$. To investigate the role of water in this mechanism, further experiments were carried out by heating a reaction mixture containing only TEA as a solvent (i.e., without water) in an autoclave at $160^{\circ} \mathrm{C}$ for $6 \mathrm{~h}$ and studying the morphology of the synthesized sample. In this case, $\mathrm{Bi}_{2} \mathrm{~S}_{3}$ nanorods with diameters and lengths in the range of 77-575 $\mathrm{nm}$ and $1200-$ $3700 \mathrm{~nm}$, respectively (Figure S3, Supporting Information), were obtained in contrast to the nanorods (diameters and lengths in the range of 44-140 $\mathrm{nm}$ and 945-2150 nm, resp.) produced under similar reaction conditions with TEA and water as reaction medium. The results validated the utility of water in the reaction medium for the generation of uniformly sized nanorods with high aspect ratio.

$\mathrm{Bi}_{2} \mathrm{~S}_{3}$ has moderately high band gap energy $\left(E_{g}\right)$ compared to the other sulfides of the same group, making them important materials for various optoelectronic applications. So, the diffuse reflectance spectrum of the $\mathrm{Bi}_{2} \mathrm{~S}_{3}$ sample prepared at optimized hydrothermal reaction conditions (i.e., at $160^{\circ} \mathrm{C}$ for $18 \mathrm{~h}$ ) has been carried out at room temperature, and the result is depicted in Figure 10. The optical band gap was calculated from the point of intersection of the tangent of the absorption edge and the extrapolated line of the diffuse reflectance at lower wavelength, and the value was found to be $1.46 \mathrm{eV}$. This calculated value lies in the band gap range reported for bulk $\mathrm{Bi}_{2} \mathrm{~S}_{3}$, which may be attributed to their larger average particle diameters compared to the exciton Bohr radius of $\mathrm{Bi}_{2} \mathrm{~S}_{3}(29.8 \mathrm{~nm})$ [46].

\section{Conclusions}

Uniformly sized single-crystalline $\mathrm{Bi}_{2} \mathrm{~S}_{3}$ nanorods with average diameters and lengths in the range of $70-170 \mathrm{~nm}$ and $0.55-3 \mu \mathrm{m}$, respectively, have been synthesized through hydrothermal reaction at a temperature as low as $160^{\circ} \mathrm{C}$. These nanorods have been found to be of pure orthorhombic phase, as evident from XRD, XPS, and Raman spectroscopy. Nanorods of $\mathrm{Bi}_{2} \mathrm{~S}_{3}$ have been generated at the expense of the amorphous precursor precipitates, formed at room temperature, which has been found to consist of aminium compounds of $\left[\mathrm{Bi}\left(\mathrm{S}_{2} \mathrm{O}_{3}\right)\right]^{3-}$ and $\left(\mathrm{BiS}_{2}\right)^{-}$. The precursors undergo decomposition and subsequent growth into 
nanorods/wires through SSS as well as oriented-aggregationgrowth process under hydrothermal conditions. It is found that $\mathrm{Bi}_{2} \mathrm{~S}_{3}$ nanorods with relatively good aspect ratio and smooth surfaces are produced, only when all the reaction conditions, such as hydrothermal temperature, incubation period, and solvents, are tuned.

\section{Acknowledgments}

The authors acknowledge their sincere thanks to Professor B. Viswanathan and Dr. K. Thirunavukkarasu of the Indian Institute of Technology Madras for their help in characterizing the samples by XPS. They also express their gratitude to Professor M. K. Panigrahi of the Indian Institute of Technology Kharagpur for obtaining Raman spectra.

\section{References}

[1] C. Ye, G. Meng, Z. Jiang, Y. Wang, G. Wang, and L. Zhang, "Rational growth of $\mathrm{Bi}_{2} \mathrm{~S}_{3}$ nanotubes from quasi-twodimensional precursors," Journal of the American Chemical Society, vol. 124, no. 51, pp. 15180-15181, 2002.

[2] S. K. Batabyal, C. Basu, A. R. Das, and G. S. Sanyal, "Nanostructures of bismuth sulphide: synthesis and electrical properties," Journal of Nanoscience and Nanotechnology, vol. 7, no. 2, pp. 565-569, 2007.

[3] J. D. Desai and C. D. Lokhande, "Chemical deposition of $\mathrm{Bi}_{2} \mathrm{~S}_{3}$ thin films from thioacetamide bath," Materials Chemistry and Physics, vol. 41, no. 2, pp. 98-103, 1995.

[4] M. T. S. Nair and P. K. Nair, "Photoconductive bismuth sulphide thin films by chemical deposition," Semiconductor Science and Technology, vol. 5, no. 12, pp. 1225-1230, 1990.

[5] G. Konstantatos, L. Levina, J. Tang, and E. H. Sergeant, "Sensitive solution-processed $\mathrm{Bi}_{2} \mathrm{~S}_{3}$ nanocrystalline photodetectors," Nano Letters, vol. 8, no. 11, pp. 4002-4006, 2008.

[6] S. C. Liufu, L. D. Chen, Q. Yao, and C. F. Wang, "Assembly of one-dimensional nanorods into $\mathrm{Bi}_{2} \mathrm{~S}_{3}$ films with enhanced thermoelectric transport properties," Applied Physics Letters, vol. 90, Article ID 112106, 3 pages, 2007.

[7] X. Yu and C. Cao, "Photoresponse and field-emission properties of bismuth sulfide nanoflowers," Crystal Growth \& Design, vol. 8, pp. 3951-3955, 2008.

[8] R. S. Mane, B. R. Sankapal, and C. D. Lokhande, "Photoelectrochemical cells based on chemically deposited nanocrystalline $\mathrm{Bi}_{2} \mathrm{~S}_{3}$ thin films," Materials Chemistry and Physics, vol. 60, no. 2, pp. 196-203, 1999.

[9] R. Suarez, P. K. Nair, and P. V. Kamat, "Photoelectrochemical behavior of $\mathrm{Bi}_{2} \mathrm{~S}_{3}$ nanoclusters and nanostructured thin films," Langmuir, vol. 14, no. 12, pp. 3236-3241, 1998.

[10] M. S. Dresselhaus, G. Chen, M. Y. Tang et al., "New directions for low-dimensional thermoelectric materials," Advanced Materials, vol. 19, no. 8, pp. 1043-1053, 2007.

[11] H. Bao, X. Cui, C. M. Li, G. Ye, J. Zhang, and J. Guo, "Photoswitchable semiconductor bismuth sulfide $\left(\mathrm{Bi}_{2} \mathrm{~S}_{3}\right)$ nanowires and their self-supported nanowire arrays," The Journal of Physical Chemistry C, vol. 111, no. 33, pp. 12279-12283, 2007.

[12] H. Bao, C. M. Li, X. Cui, Q. Song, H. Yang, and J. Guo, "Single-crystalline $\mathrm{Bi}_{2} \mathrm{~S}_{3}$ nanowire network film and its optical switches," Nanotechnology, vol. 19, no. 33, Article ID 335302, 2008.
[13] Y. W. Koh, C. S. Lai, A. Y. Du, E. R. T. Tiekink, and K. P. Loh, "Growth of bismuth sulfide nanowire using bismuth trisxanthate single source precursors," Chemistry of Materials, vol. 15, no. 24, pp. 4544-4554, 2003.

[14] M. B. Sigman Jr. and B. A. Korgel, "Solventless synthesis of $\mathrm{Bi}_{2} \mathrm{~S}_{3}$ (bismuthinite) nanorods, nanowires, and nanofabric," Chemistry of Materials, vol. 17, pp. 1655-1660, 2005.

[15] X. S. Peng, G. W. Meng, J. Zhang et al., "Electrochemical fabrication of ordered $\mathrm{Bi}_{2} \mathrm{~S}_{3}$ nanowire arrays," Journal of Physics D, vol. 34, no. 22, pp. 3224-3228, 2001.

[16] Z. P. Liu, J. B. Liang, S. Li, S. Peng, and Y. T. Qian, "Synthesis and growth mechanism of $\mathrm{Bi}_{2} \mathrm{~S}_{3}$ nanoribbons," European Journal of Chemistry, vol. 10, no. 3, pp. 634-640, 2004.

[17] H. Zhang, Y. Ji, X. Y. Ma, J. Xu, and D. Yang, "Long $\mathrm{Bi}_{2} \mathrm{~S}_{3}$ nanowires prepared by a simple hydrothermal method," Nanotechnology, vol. 14, no. 9, pp. 974-977, 2003.

[18] J. Jiang, S. H. Yu, W. T. Yao, H. Ge, and G. Z. Zhang, "Morphogenesis and crystallization of $\mathrm{Bi}_{2} \mathrm{~S}_{3}$ nanostructures by an ionic liquid-assisted templating route: synthesis, formation mechanism, and properties," Chemistry of Materials, vol. 17, no. 24, pp. 6094-6100, 2005.

[19] T. Thongtem, A. Phuruangrat, S. Wannapop, and S. Thongtem, "Characterization of $\mathrm{Bi}_{2} \mathrm{~S}_{3}$ with different morphologies synthesized using microwave radiation," Materials Letters, vol. 64, no. 2, pp. 122-124, 2010.

[20] L. Tian, H. Y. Tan, and J. J. Vittal, "Morphology-controlled synthesis of $\mathrm{Bi}_{2} \mathrm{~S}_{3}$ nanomaterials via single- and multiple-source approaches," Crystal Growth \& Design, vol. 8, no. 2, pp. 734-738, 2008.

[21] J. Wu, F. Qin, G. Cheng et al., "Large-scale synthesis of bismuth sulfide nanorods by microwave irradiation," Journal of Alloys and Compounds, vol. 509, no. 5, pp. 2116-2126, 2011.

[22] H. S. Yu, J. Yang, Y. S. Wu, Z. H. Han, Y. Xie, and Y. T. Qian, "Hydrothermal preparation and characterization of rod-like ultrafine powders of bismuth sulfide," Materials Research Bulletin, vol. 33, no. 11, pp. 1661-1666, 1998.

[23] Y. Deng, C. W. Nan, and L. Guo, "A novel approach to $\mathrm{Bi}_{2} \mathrm{Te}_{3}$ nanorods by controlling oriented attachment," Chemical Physics Letters, vol. 383, no. 5-6, pp. 572-576, 2004.

[24] J. R. Ota and S. K. Srivastava, "Polypyrrole coating of Tartaric acid-assisted synthesized $\mathrm{Bi}_{2} \mathrm{~S}_{3}$ nanorods," The Journal of Physical Chemistry C, vol. 111, no. 33, pp. 12260-12264, 2007.

[25] R. Chen, M. H. So, C. M. Che, and H. Sun, "Controlled synthesis of high crystalline bismuth sulfide nanorods: using bismuth citrate as a precursor," Journal of Materials Chemistry, vol. 15, no. 42, pp. 4540-4545, 2005.

[26] G. Z. Shen, D. Chen, K. B. Tang, F. Q. Li, and Y. T. Qian, "Large-scale synthesis of uniform urchin-like patterns of $\mathrm{Bi}_{2} \mathrm{~S}_{3}$ nanorods through a rapid polyol process," Chemical Physics Letters, vol. 370, no. 3-4, pp. 334-337, 2003.

[27] H. Zhang and L. Wang, "Synthesis and characterization of $\mathrm{Bi}_{2} \mathrm{~S}_{3}$ nanorods by solvothermal method in polyol media," Materials Letters, vol. 61, no. 8-9, pp. 1667-1670, 2007.

[28] A. Pathak, S. Mohapatra, S. Mohapatra et al., "Preparation of nanosized mixed-oxide powders," American Ceramic Society Bulletin, vol. 83, no. 8, pp. 9301-9306, 2004.

[29] H. Wang, J. J. Zhu, J. M. Zhu, and H. Y. Chen, "Sonochemical method for the preparation of bismuth sulfide nanorods," The Journal of Physical Chemistry B, vol. 106, no. 15, pp. 3848-3854, 2002. 
[30] A. Jana, C. Bhattacharya, S. Sinha, and J. Datta, "Study of the optimal condition for electroplating of $\mathrm{Bi}_{2} \mathrm{~S}_{3}$ thin films and their photoelectrochemical characteristics," The Journal of Solid State Electrochemistry, vol. 13, no. 9, pp. 1339-1350, 2009.

[31] J. Grigas, E. Talik, and V. Lazauskas, "X-ray photoemission spectra and electronic structure of $\mathrm{Bi}_{2} \mathrm{~S}_{3}$ crystals," Physica Status Solidi B, vol. 232, pp. 220-230, 2002.

[32] O. Rabin, J. M. Perez, J. Grimm, G. Wojtkiewicz, and R. Weissleder, "An X-ray computed tomography imaging agent based on long-circulating bismuth sulphide nanoparticles," Nature Materials, vol. 5, pp. 118-122, 2006.

[33] J. R. Ota and S. K. Srivastava, "Low temperature micelletemplate assisted growth of $\mathrm{Bi}_{2} \mathrm{~S}_{3}$ nanotubes," Nanotechnology, vol. 16, pp. 2415-2419, 2005.

[34] M. S. Bhadraver, "Physico-chemical studies on the composition of thiosulfates of metals. I. Thermometric studies of bismuth thiosulfate complexes," Bulletin of the Chemical Society of Japan, vol. 35, no. 11, pp. 1768-1770, 1962.

[35] X. H. Liao, H. Wang, J. J. Zhu, and H. Y. Chen, "Preparation of $\mathrm{Bi}_{2} \mathrm{~S}_{3}$ nanorods by microwave irradiation," Materials Research Bulletin, vol. 36, no. 13-14, pp. 2339-2346, 2001.

[36] W. B. Zhao, J. J. Zhu, Y. Zhao, and H. Y. Chen, "Photochemical synthesis and characterization of $\mathrm{Bi}_{2} \mathrm{~S}_{3}$ nanofibers," Materials Science and Engineering B, vol. 110, no. 3, pp. 307-313, 2004.

[37] W. F. Egelhoff Jr., " $\mathrm{N}_{2}$ on $\mathrm{Ni}(100)$ : angular dependence of the N1s XPS peaks," Surface Science, vol. 141, no. 2-3, pp. L324-L328, 1984.

[38] R. Malakooti, L. Cademartiri, Y. Akcakir, S. Petrov, A. Migliori, and G. A. Ozin, "Shape-Controlled $\mathrm{Bi}_{2} \mathrm{~S}_{3}$ anocrystals and their plasma polymerization into flexible films," Advanced Materials, vol. 18, no. 16, pp. 2189-2194, 2006.

[39] C. D. Wagner, W. M. Riggs, L. E. Davis, and J. F. Moulder, Handbook of X-Ray Photoelectron Spectroscopy, Edited by G. E. Mulenberg, Perkin-Elmer, Minneapolis, Minn, USA, 1979.

[40] P. K. Panigrahi and A. Pathak, "Microwave-assisted synthesis of $\mathrm{WS}_{2}$ nanowires through tetrathiotungstate precursors," Science and Technology of Advanced Materials, vol. 9, no. 4, Article ID 045008, 2008.

[41] G. Q. Zhu, P. Liu, J. P. Zhou et al., "Effect of mixed solvent on the morphologies of nanostructured $\mathrm{Bi}_{2} \mathrm{~S}_{3}$ prepared by solvothermal synthesis," Materials Letters, vol. 62, no. 15, pp. 2335-2338, 2008.

[42] B. Gates, Y. Yin, and Y. Xia, "A solution-phase approach to the synthesis of uniform nanowires of crystalline selenium with lateral dimensions in the range of 10-30 nm," Journal of the American Chemical Society, vol. 122, no. 50, pp. 12582-12583, 2000.

[43] Y. Yu, C. H. Jin, R. H. Wang, Q. Chen, and L. M. Peng, "High-quality ultralong $\mathrm{Bi}_{2} \mathrm{~S}_{3}$ nanowires: structure, growth, and properties," The Journal of Physical Chemistry B, vol. 109, no. 40, pp. 18772-18776, 2005.

[44] A. K. Singh, V. Viswanath, and V. C. Janu, "Synthesis, effect of capping agents, structural, optical and photoluminescence properties of $\mathrm{ZnO}$ nanoparticles," Journal of Luminescence, vol. 129, no. 8, pp. 874-878, 2009.

[45] M. S. Mohajerani, M. Mazloumi, A. Lak, A. Kajbafvala, S. Zanganeh, and S. K. Sadrnezhaad, "Self-assembled zinc oxide nanostructures via a rapid microwave-assisted route," Journal of Crystal Growth, vol. 310, no. 15, pp. 3621-3625, 2008.

[46] B. Pejova and I. Grozdanov, "Structural and optical properties of chemically deposited thin films of quantum-sized bismuth(III) sulfide," Materials Chemistry and Physics, vol. 99, no. 1, pp. 3949, 2006. 

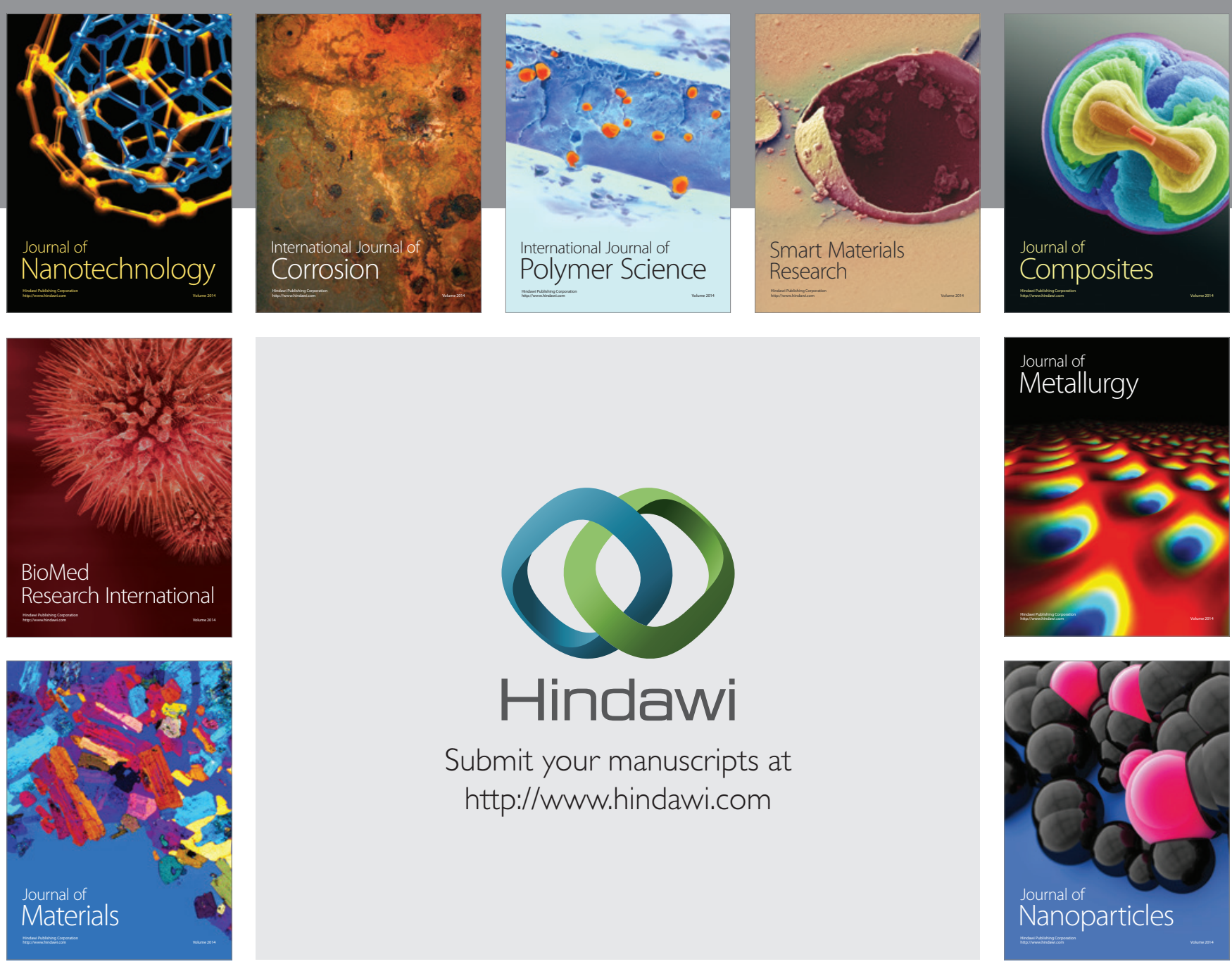

Submit your manuscripts at http://www.hindawi.com
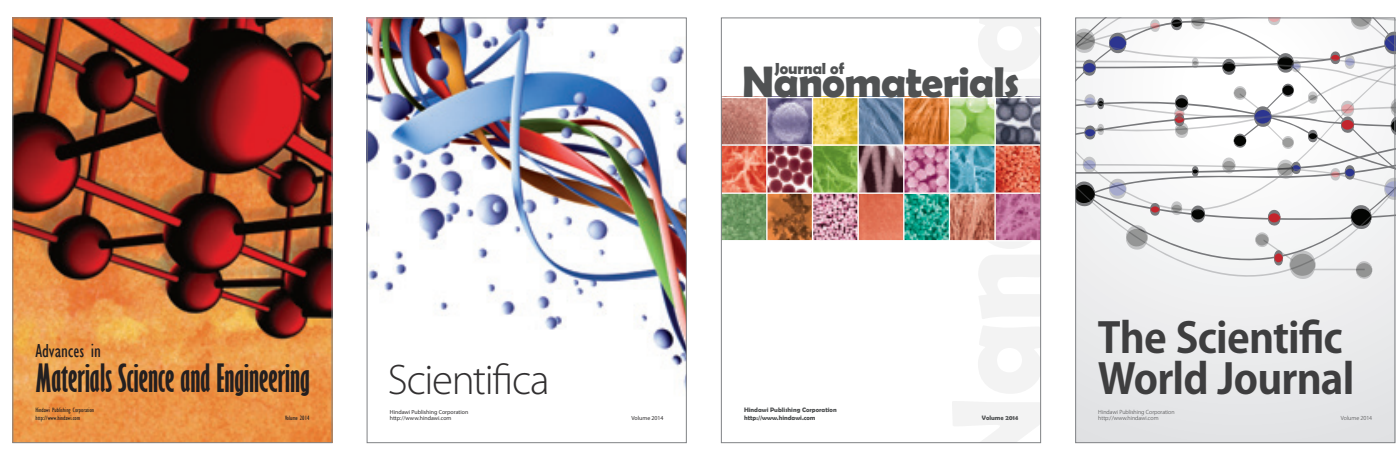

\section{The Scientific World Journal}
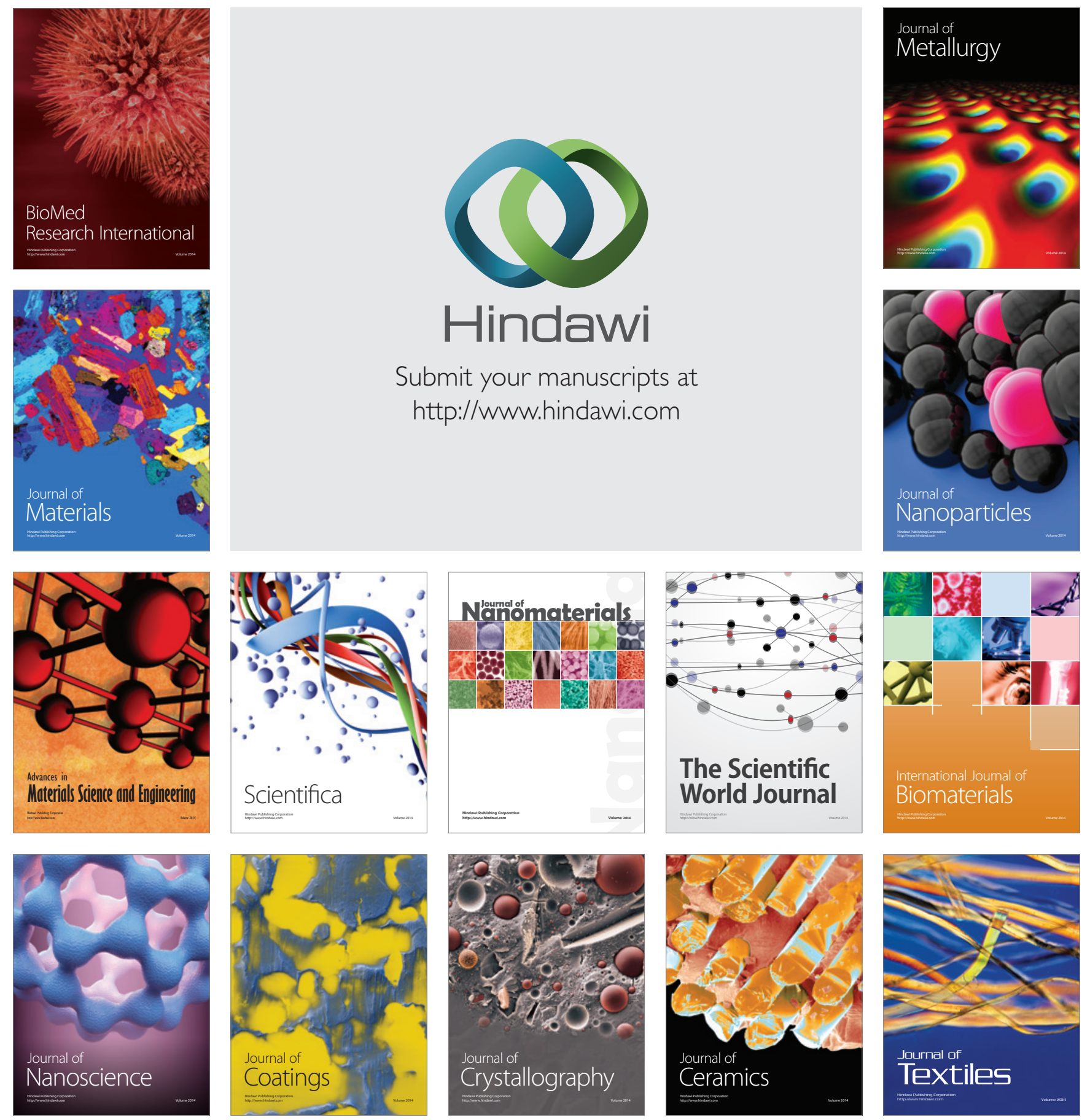